\title{
MASSIVE PULMONARY FIBROSIS FROM THE INHALATION OF TALC
}

\author{
BY \\ A. C. HUNT \\ From the Department of Forensic Medicine, The London Hospital Medical College
}

(RECEIVED FOR PUBLICATION FEBRUARY 4, 1956)

It is generally accepted that the inhalation of commercial talc powders can occasionally produce pulmonary disease. This is usually fibrosis of a nodular type, and only a few examples of massive fibrosis have been reported, most of them without pathological description. This is the report of one such case showing certain unusual features.

\section{CASE REPORT}

INDUSTRIAL HisToRY.-The patient was 57 years old at his death. He joined the Army at the age of 16 , at the start of the first world war. During this war he was gassed, although not severely. When he left the Army he became a storekeeper in a food store. In 1927 , at the age of 29 , he first entered the accumulator industry. For the first six years he was employed in lead burning, and was not exposed to dust. After this he joined another firm as a plate caster. The following 10 years, i.e., between the ages of 35 and 45 , was the only period during which he was exposed to dust. Lead accumulator plates were cast in a hand-operated mould consisting of two faces hinged at the bottom. There were two men casting in one small room, each with his own mould and with a communal gas-fired lead pot. The mould was at about waist height. It was opened, and then each surface was roughly dusted with talc from a loosely woven calico bag or an old sock. The bag was banged hard against the mould and a cloud of dust would arise. Next, the mould was closed and the lead poured in. It was cooled with water and opened and the plate removed. The sequence was then repeated. The patient was a good workman and cast up to 110 plates an hour, being paid piece rates. The talc bag contained about three-quarters of a pound of talc, and about three bags were used in two days. There was no dust extraction in the room, and everything was covered with talc dust. The source of the talc used cannot be traced, except for the last two years of this period, when it was obtained from Manchuria, Canada, or Egypt. The plates are now cast automatically in this factory and the mould faces are dressed with a cork compound ; there is no dust risk whatever.

After 10 years of this work the patient was engaged, for 12 years before his death, in battery assembly and charging and occasionally in plate casting. The amount of talc dust to which he was exposed for these years was negligible.

Clinical History.-Despite the gross radiological changes his physical state was remarkably good. He first came under observation as an out-patient of the Miller General Hospital, Greenwich, nine years before his death, when he was examined because his son developed pulmonary tuberculosis. During the last 10 years of his life he had several attacks of "bronchitis," with cough and sputum and pyrexia. These were treated at home with early recovery. Apart from these attacks he had a slight morning cough, productive of a jelly-like, greyish sputum. He was not breathless on normal exertion. Nine months before death all the metacarpo-phalangeal joints of both hands became swollen and painful, with slight ulnar deviation of the fingers. The left ankle was transiently swollen. There was no spindling of the interphalangeal joints, and at this time there was early clubbing of the fingers. His hands were radiographed when he was first seen to exclude the bony changes of sarcoidosis, and again, together with other joints, when the knuckles became swollen. None of these radiographs showed any bony abnormality. Clinically the joint changes were considered to be manifestations of pulmonary osteoarthropathy. Unfortunately, no joints were examined histologically after death, and it is impossible to exclude rheumatoid arthritis. It would have been of interest to make this exclusion, in view of Caplan's (1953) observation of the modification of coal-miners' pneumoconiosis in men with rheumatoid arthritis. The only physical signs recorded in the chest during the period of observation were occasional râles, especially over the right lung. Sputa were examined for tubercle bacilli by microscopy and culture repeatedly during these nine years. Between four and six groups of sputa were examined yearly, and no tubercle bacilli were ever found. The sedimentation rate was estimated at regular intervals, and was on most occasions moderately raised but sometimes normal. The Mantoux reaction was positive at a dilution of $1: 10,000$. An electrocardiograph taken three months before death showed no definite right ventricular preponderance. An axillary lymph node was removed for biopsy six years before death, to investigate the possibility of sarcoidosis. There were a few doubly refractile 


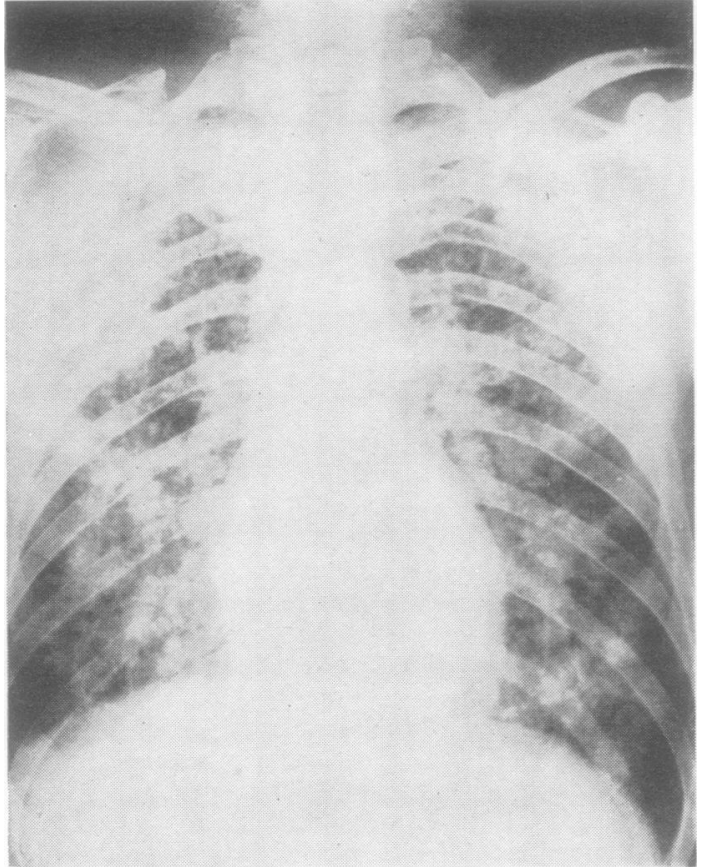

FIG. 1.-Radiograph of chest nine years before death.

particles in the lymphatic sinuses resembling the talc particles found in the lung at necropsy, but no other abnormality. During the last year of his life he had occasional fainting attacks on exertion. On the day

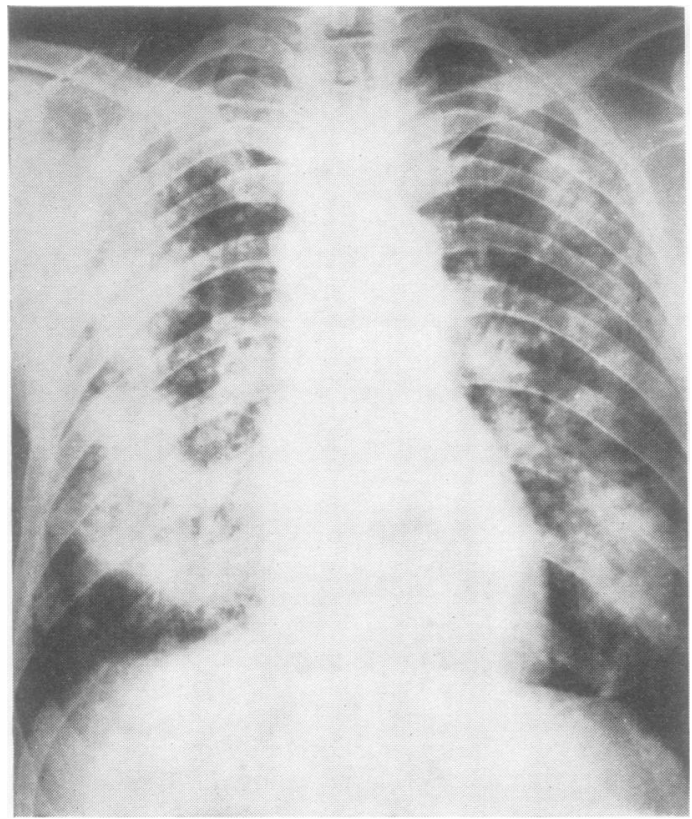

FIG. 3.-Radiograph of chest five years before death.

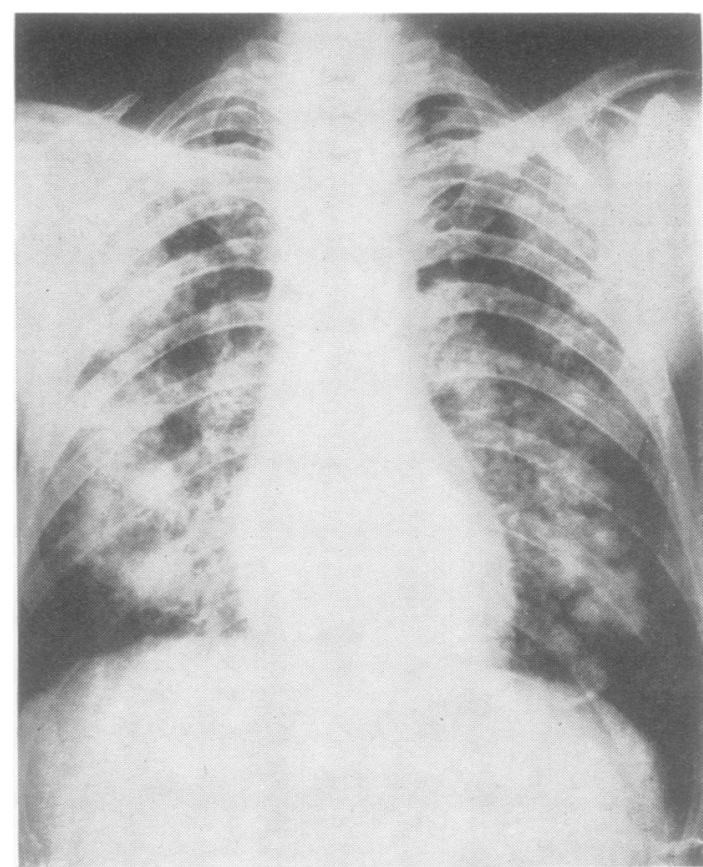

FIG. 2.-Radiograph of chest seven years before death.

of his death he had dug potatoes in the morning and eaten a large lunch. Shortly after the meal he was found dead in a lavatory, having defaecated. He was seen to be quite well immediately before this.

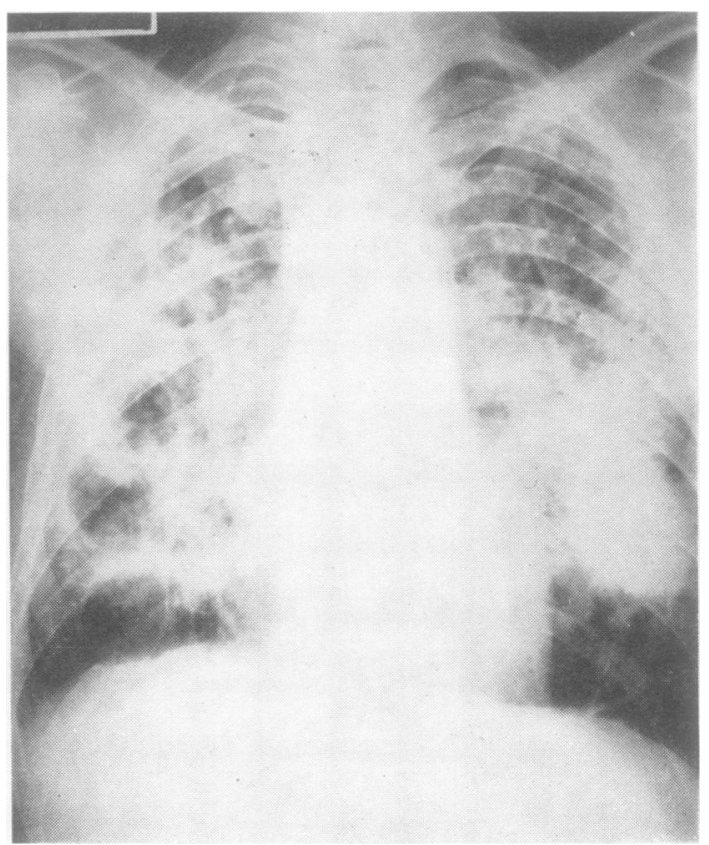

FIG. 4.-Radiograph of chest two months before death. 
Radiological Appearances.-Radiographs (Figs. 1-4) were taken of the chest at intervals of three to four months throughout the last nine years of his life. In the earlier films there were numerous faint small opacities (average diameter $0.3 \mathrm{~cm}$.) scattered throughout the lung fields. They were most closely set around the borders of the cardiac shadow and the hila in the postero-anterior views. In the right lower and middle zones were four ill-defined larger mottled opacities, each about $2 \mathrm{~cm}$. diameter. There were several similar smaller opacities in the left lower lobe. There was no evidence of cavitation at this time.

During the succeeding years the larger opacities increased in size and gradually became confluent. Those in the left lower lobe had become a single large mass ( 7 by $4 \mathrm{~cm}$.) within four years. By this time, also, the first signs of cavitation in the confluent opacities in the right lower and middle zone had appeared. The smaller nodules also enlarged, and lost their discrete outline, producing a lattice-like picture.

By the time of death there were large opacities occupying the middle two-thirds of both lung fields, and the cavities in the right middle zone could be clearly seen. The lower edge of the opacity in the right lung had assumed a stellate pattern, with dense streaks extending towards the distorted diaphragm. The heart shadow was not appreciably enlarged and the trachea remained central.

Post-MORTEM EXAMINATION.-The body was that of a fairly well nourished man. There was slight

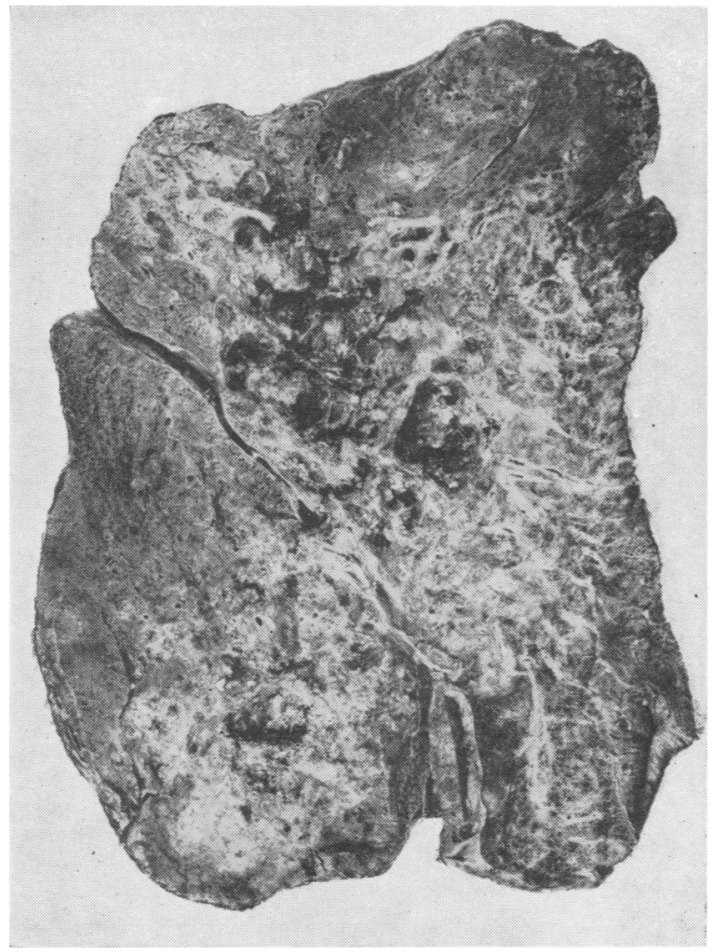

Fig. 5.-Sagittal section of left lung.

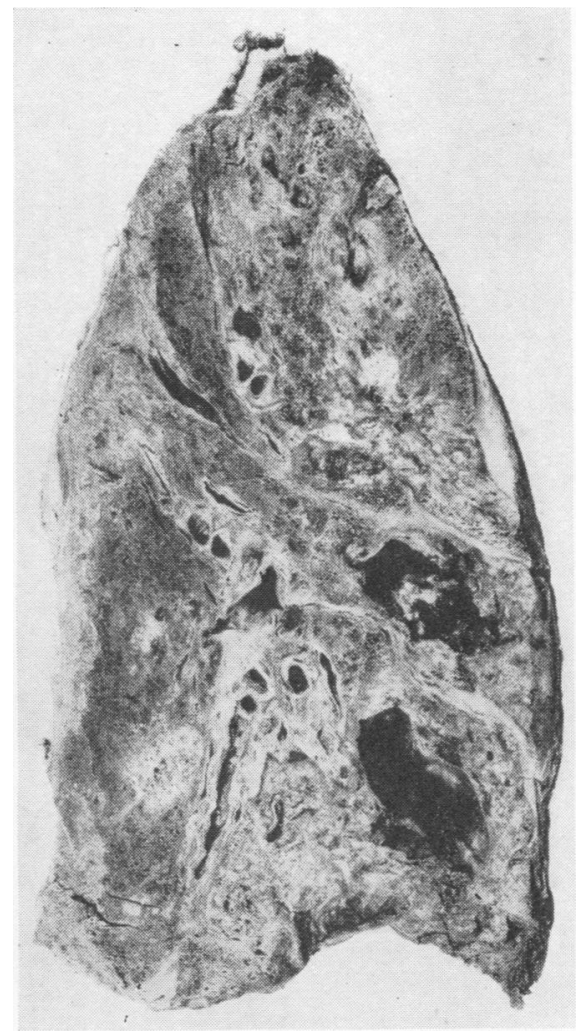

FIG. 6.-Sagittal section of right lung.

swelling of the metacarpo-phalangeal joints. but no spindling of the interphalangeal joints. There was slight clubbing of the fingers. The right ventricle was slightly hypertrophied only $(0.5-0.6 \mathrm{~cm}$. thick in the conus) and not dilated. The heart weighed $340 \mathrm{~g}$. The valves were normal. There were a few flecks of atheroma in the pulmonary arteries. The other organs were normal. There was nothing to account for his sudden death, apart from the changes in the lungs, and it was considered that death had occurred from acute cardiac failure.

There were dense fibrous adhesions over all surfaces of both lungs. and partial obliteration of the fissures of the left lung. Both lungs were firm and heavy; the left weighed $1,030 \mathrm{~g}$. and the right $915 \mathrm{~g}$.

Left Lung (Fig. 5).--There was a hard mass in both lobes reaching the hilum, not involving the apical segment of either lobe, and reaching to within $2 \mathrm{~cm}$. of the pleura of the anterior and lateral surfaces, and to about $4 \mathrm{~cm}$. of the posterior surfaces. The cut surface of the mass was whitish-grey with paler bands running through it. There were a few islands of greatly emphysematous firm lung in the mass, and the outer edge was roughly lobulated. Especially at the periphery, individual nodules, up to about a centimetre in diameter, could be identified by palpation. There was an irregular cavity in the fibrous mass in 


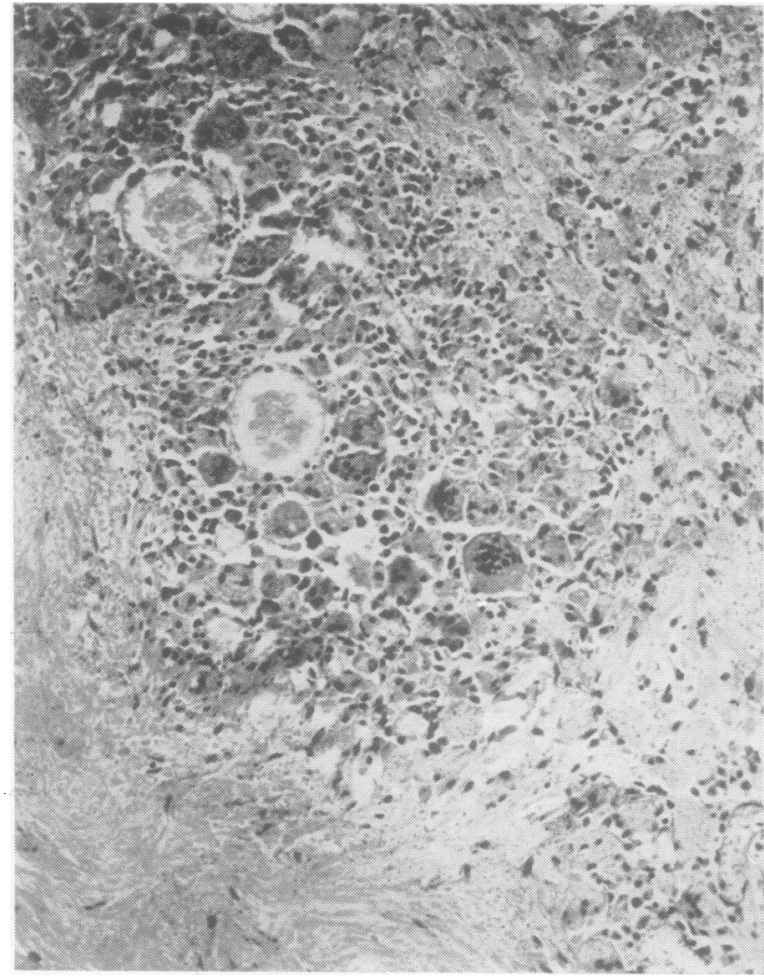

Fig. 7.-Giant-cell granulomatous seam. (Haematoxylin and eosin, $\times$ 130.)

the upper lobe ( 8 by 5 by $3 \mathrm{~cm}$.), the long axis of which ran antero-posteriorly. The wall of the cavity was trabeculated and the lining rough and slightly gritty to the touch. The centre of the fibrosis in the lower lobe was breaking down in an area of about $4 \mathrm{~cm}$. diameter, where it was of similar colour to the remaining fibrosis, but friable. The remaining lung was emphysematous, and scattered in it were illdefined firm nodules varying from a pin's head to $1.5 \mathrm{~cm}$. in diameter. The centres of most of these larger nodules were also soft and friable. There was slight diffuse cylindrical bronchiectasis throughout the lung.

Right Lung (Fig. 6).-There was a similar mass extending from the hilum to within $3 \mathrm{~cm}$. of the pleura of the posterior surface but reaching the pleura of the lateral surface of the lower lobe. The mass was more obviously nodular than on the left. The fibrosis appeared denser around the larger bronchi, especially in the lower lobe. There was a cavity $(9$ by $3 \mathrm{~cm}$.) in the mass in the lower lobe, mainly in the anterior basal segment. It consisted of a honeycomb of interconnecting large spaces with a smooth, shiny black lining. There was a smaller cavity in the right middle lobe which was similarly lined, except for a few areas in which the lining was rough and granular. Small patches of necrosis were visible with the naked eye in the fibrosis in the upper? lobe, and there were similar nodules in the remaining lung, as in the left lung, and the centres of many of $\frac{\bar{c}}{\sigma}$ these were also friable.

Histology.-Running throughout the confluent 0 masses were thick cellular seams of macrophages and well-formed multinucleate giant cells of a foreign $\vec{\circ}$ body type (Fig. 7). The giant cells, and most of the $\overrightarrow{-}$ macrophages, were packed with doubly refractile $\omega^{\prime}$ particles when viewed by polarized light (Fig. 8). These particles were predominantly needle-shaped and $x$ 5-10 $\mu$ long. The seams were broadest at the periphery of the masses, where they were up to $0.5 \mathrm{~cm}$. in diameter and varying from a few millimetres to a i centimetre or more apart. The rest of each mass $\stackrel{\infty}{y}$ was fibrous tissue containing large areas of necrosis. 음 Some of these areas were composed of amorphous? finely granular material stained yellow with van $\vec{\nabla}$ Gieson's stain and pink with eosin. Sometimes $\mathbb{D}$ surviving macrophages were present at the edges, and $\Phi$ a few poorly fuchsinophil strands were still visible. Doubly refractile particles were present in large $\stackrel{\mathbb{D}}{-}$ numbers, often greatest at the periphery (Fig. 9). In $\overrightarrow{0}$ places the amorphous material was in aggregates the size and shape of necrotic cells, and these areas. appeared to have been formed by necrosis in the

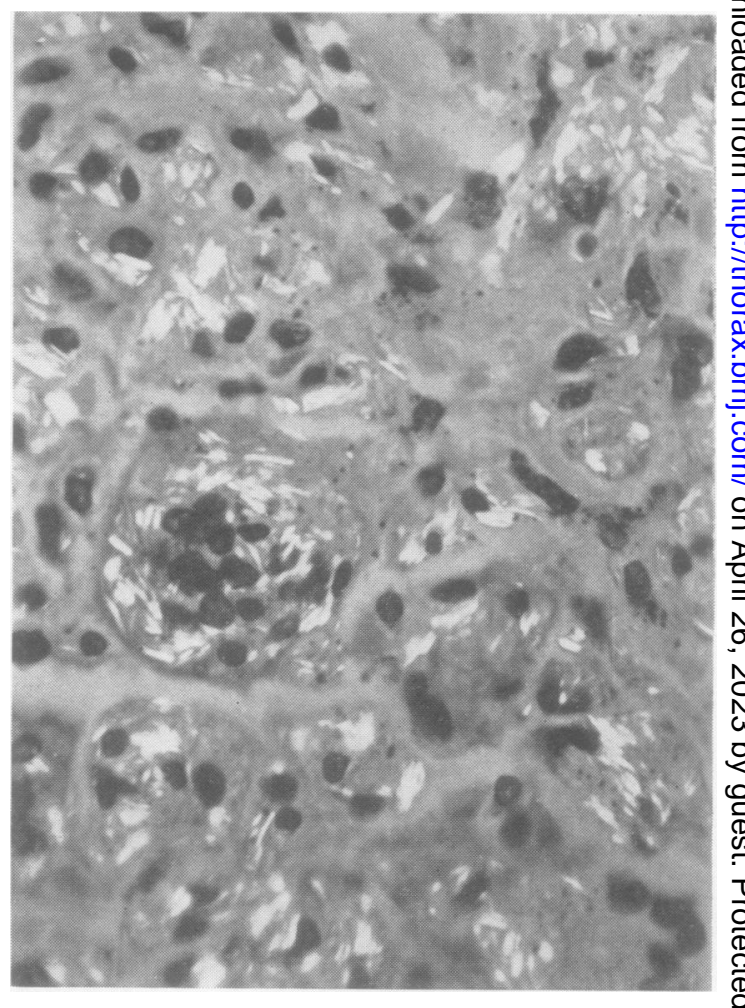

FIG. 8.-Giant cells laden with doubly refractile particles. Photograph obtained by exposure with and without polarization of light. (Haematoxylin and eosin, $\times 650$.) 


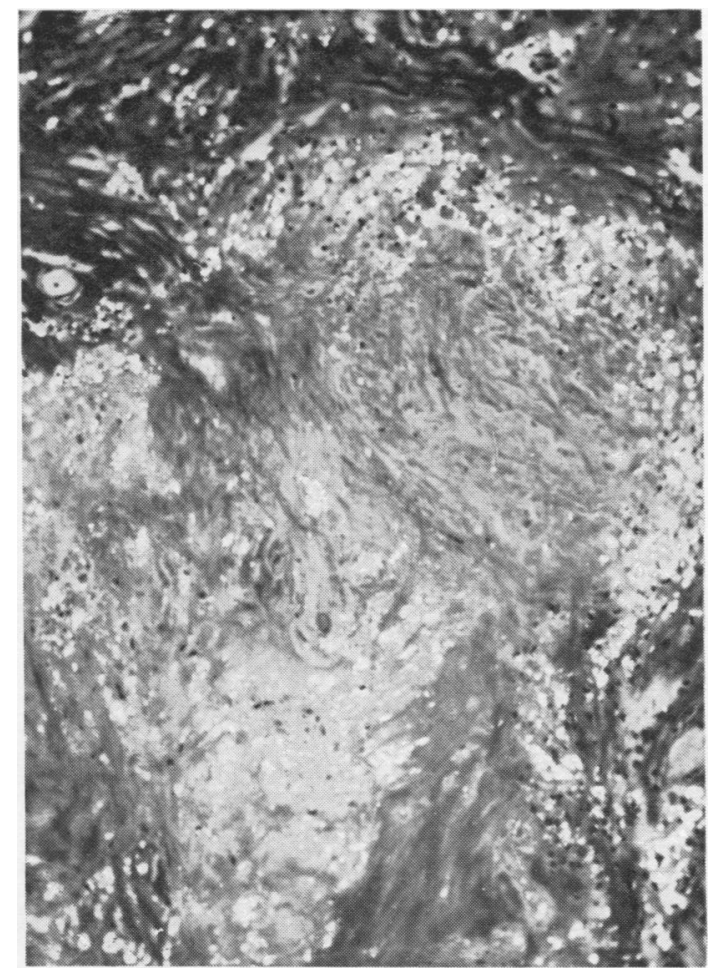

FIG.9.-Areas of necrosis and loss of staining in collagen. (Van Gieson, $\times 110$, photographed as Fig. 8.)

cellular seams. Apart from this frank necrosis there were widespread large patches in the fibrosis where the collagen fibres were swollen and blurred, stained pale orange with van Gieson's stain, and were separated by similar amorphous debris to that in the areas mentioned above, and also contained doubly refractile material. None of the necrotic patches stained positively for fibrin, and the periodic-acid-Schiff reaction was negative. There was a fine network of argyrophil fibrils in most of the necrotic areas.

Especially at the periphery of the masses, and in relation to the blood vessels, the fibrosis was not necrotic, and often the bundles of collagen were broken up by intervening narrow bands of cells usually containing talc particles. The blood vessels in relation to the fibrous masses showed severe endarteritis fibrosa, and some smaller vessels entirely permeated by fibrosis could be picked out by the remains of their elastic tissue. Only a few fragments of the remains of alveolar elastic tissue were found in the fibrosis, except at the periphery. The cavities in the left lung were lined by necrotic debris, except in a few places, where collections of dust-laden phagocytes formed the wall. Scattered in the necrosis around the cavities were numerous strongly basophilic roughly spherical granular bodies, up to half a millimetre in diameter, stained intensely for free iron by
Perles's reaction, and for calcium by von Kossa's method. Throughout the fibrous parts of the lungs were a few macrophages containing free iron, and there were small particles in the non-cavitated necrosis. The cavities in the right lung were similar to those in the left upper lobe, except that there was a thin layer of fuchsinophil collagen superficial to the necrotic and cellular elements and forming the smooth lining. The earliest lesions in the remaining lung were small interstitial cellular foci containing fine collagen strands, mostly related to small vessels (Fig. 10). There were also patches of diffuse interstitial fibrosis, often associated with smaller nodules. The larger discrete nodules were similar to the confluent masses. The fibrous tissue forming them was not whorled, and the centres were frequently necrotic. In these discrete nodules the foreign body giant-cell reaction was not so marked a feature.

Curious bodies (McLaughlin, Rogers, and Dunham, 1949), similar but not identical to asbestos bodies, have been described in most cases of talc pneumoconiosis. They consist of a single fibre, with terminal rosettes, but without intermediate beading. They were present in this case, although in small numbers (Fig. 11). No acid-fast bacilli were seen in any of the sections.

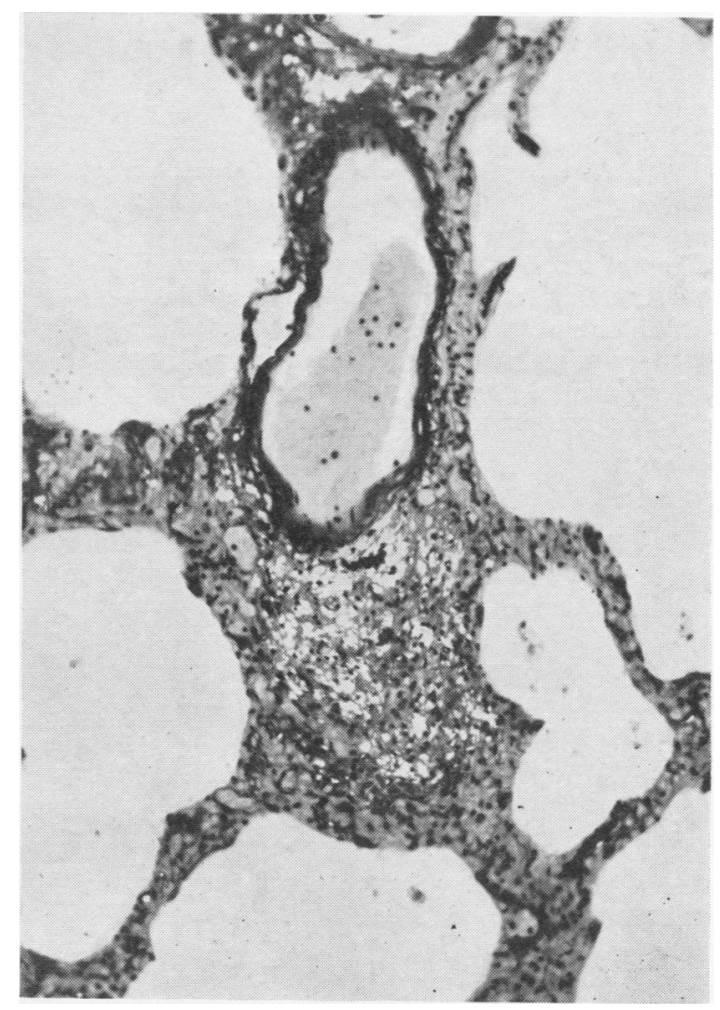

FIG. 10.-Early lesion in relation to blood vessel. (Van Gieson, $\times 110$, photographed as Fig. 8.) 


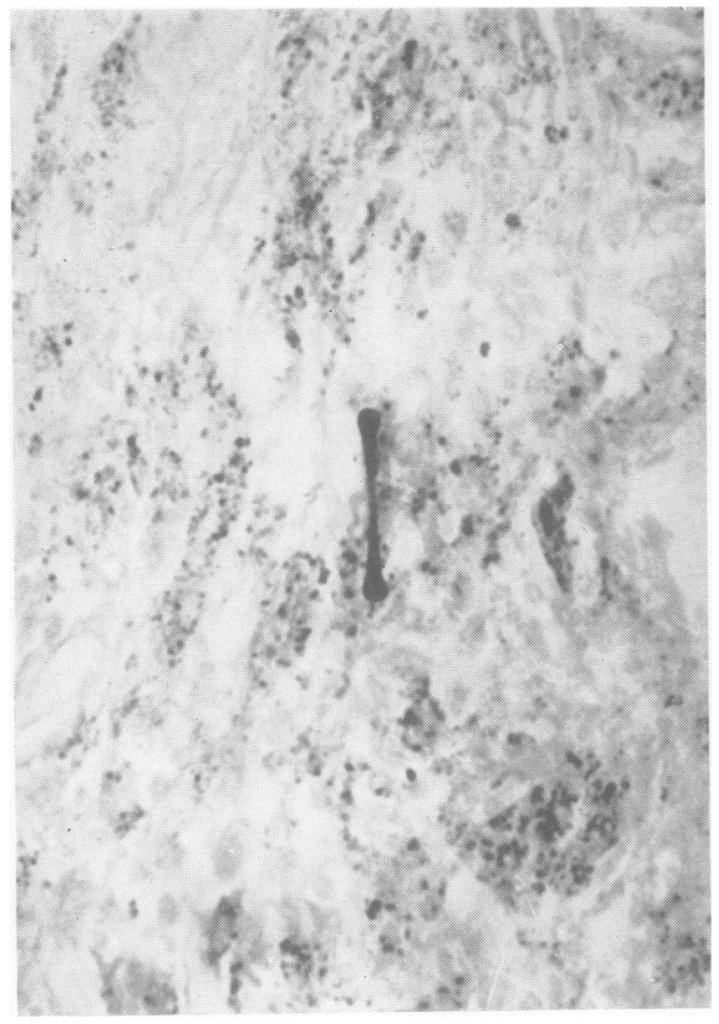

FIG. 11.-Asbestos-like body. (Perles's iron reaction, $\times 490$.)

There was diffuse alveolar emphysema throughout the surviving lung tissue, and the alveolar ducts and bronchioles were dilated. There were talc particles in the sinuses of the hilar glands, and some of the intrasegmental glands were largely replaced by fibrosis and talc-containing macrophages.

\section{Mineralogical Examination and ANALYsis}

Dr. G. Nagelschmidt, of the Safety in Mines Research Establishment, Ministry of Fuel and Power, examined large samples of formalin-fixed material from all lobes, which represented the various consistencies of lung tissue in roughly proportional amounts to the complete lungs. The dust was isolated by treatment with concentrated hydrogen peroxide followed by washing with alcohol and $\mathrm{N} / 10 \mathrm{HCl}$.

The weight of the dust recovered in this way was $16-17 \%$ of the dry weight or $3.5 \%$ of the wet weight. With the total wet weight of both lungs of $1,945 \mathrm{~g}$., this would correspond to $68 \mathrm{~g}$. of dust. The dust was pale grey and lost only $1 \%$ on prolonged ashing at $380^{\circ} \mathrm{C}$.

$X$-ray diffraction diagrams showed a strong talc pattern, and a few weak kaolin lines, and very faintly

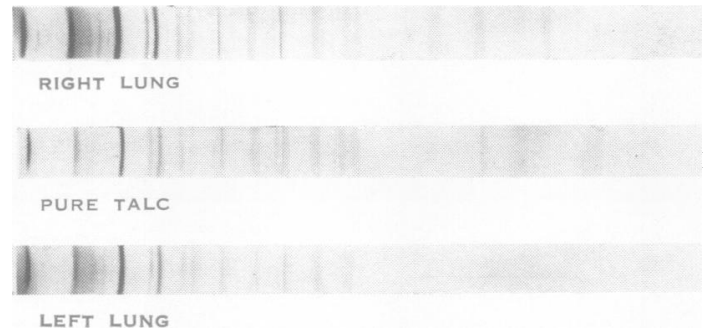
FIG. 12.- $X$-ray diffraction patterns of lung residues. (Crown

the strongest quartz line at $3.34^{\circ} \mathrm{A}$. This indicates that the sample contained, apart from talc, less than $0.5 \%$ of quartz, and perhaps 2 or $3 \%$ of kaolin (Fig. 12). There was no evidence of the presence of tremolite. Comparison of the talc from the lungs with samples of known origin showed a likeness to those from Egypt, Italy, or China, but not to those from Norway, Sweden, U.S.A., Canada, Austria, India, or the French Pyrenees.

Partial chemical analysis gave the following results :

\begin{tabular}{|c|c|c|c|}
\hline & & Lung Residue & Talc (Theoretical) \\
\hline \multirow[t]{2}{*}{$\begin{array}{l}\mathrm{S}_{1} \mathrm{O}_{2} \\
\mathrm{MgO} \\
\mathbf{I g n} \text {. loss } \\
\mathrm{Al}_{2} \mathrm{O}_{3} \\
\mathrm{Fe}_{2} \mathrm{O}_{3} \\
\mathrm{~T}_{1} \mathrm{O}_{2} \\
\mathrm{CaO}^{2}\end{array}$} & $\begin{array}{ll}\ldots & \ldots \\
\cdots & \cdots \\
. & \ldots \\
. & \ldots \\
. & \ldots \\
\cdots & \ldots\end{array}$ & $\begin{array}{r}59 \cdot 3 \\
29.5 \\
6.2 \\
1.0 \\
1.0 \\
0 \cdot 3 \\
0.3\end{array}$ & $\begin{array}{r}63.4 \\
31.8 \\
4.8\end{array}$ \\
\hline & & $97 \cdot 6$ & $100 \cdot 0$ \\
\hline
\end{tabular}

This agrees with over $90 \%$ of talc.

Electron photomicrographs showed typical talc plates, and the diameters of the largest particles were of the order of 10 to $15 \mu$ (Fig. 13). There was no evidence of erosion of the surfaces of the plates.

\section{Discussion}

Commercial talc is a mixture of the pure 은 mineral talc (hydrated magnesium silicate) with $\frac{D}{0}$ related minerals such as dolomite, serpentine, anthophyllite, and tremolite. The amount of $N$ pure talc in commercial specimens is very variable. Very few samples contain any free $\mathcal{N}$ quartz. Most cases of pneumoconiosis from $\omega$ such minerals have been reported in miners and $\widetilde{F}$ millers of talc. The majority of studies are of $\bullet$ clinical and radiological findings, and only a limi- $\mathbb{\Phi}$ ted number of descriptions of the pathological $\stackrel{?}{+}$ changes are available.

In 1934 Merewether found radiographic appear- $\frac{\vec{P}}{\Phi}$ ances suggestive of diffuse interstitial fibrosis in $\stackrel{+}{+}$ 11 workers in rubber tyre manufacture. In a $\unrhd$ survey of two talc mines in Georgia, Dreessen and Dalla Valle (1935) found 16 men with radiologi- 


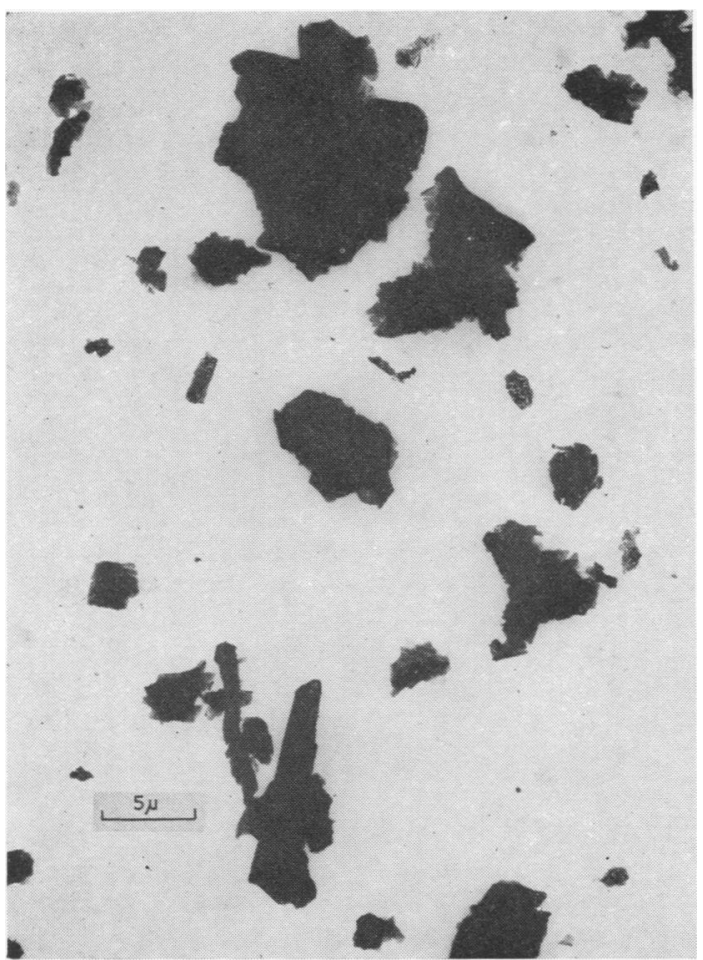

Fig. 13.-Electron photomicrographs of residue from lung, $\times 4,000$. (Crown copyright.)

cal changes. Porro, Patton, and Hobbs (1942) described the necropsies of five of 15 cases diagnosed radiologically in the Georgia mines. There were poorly outlined bands and nodules of fibrous tissue infiltrated with macrophages throughout the lungs, greatest in the middle lung fields. Mineralogical and chemical studies are not given. Soft haziness and finely granular or nodular appearances, most marked in the mid-lung fields and the bases, were observed in the radiographs of 32 of 221 workers in the tremolite talc mines of St. Lawrence County, New York, by Siegal, Smith, and Greenburg (1943). They also described peripheral "talc plaques" in $6.3 \%$ of the whole series. Slight changes were seen in 35 of 90 workers in the talc mines of Ariege (Sorel, Lasserre, and Salvador, 1943). These authors considered that talc pneumoconiosis occurred only if the lungs were previously damaged, and included war gassing as one such cause. It is of possible significance that this man was gassed in the first world war. Fine punctate shadows were present in the chest radiographs of five of 21 accumulator plate casters examined by Reichmann (1944), and in a further seven there were mesh-like markings and enlarged hilar shadows.
Perry (1947) showed mainly peripheral and basal small nodular shadows in the lungs of two men exposed to talc in a rubber tyre factory. Similar cases have been described in the cosmetic industry (Millman, 1947; Shatalov, 1954), in textile workers (Mann and Deasy, 1954), and in a parachute rigger (Lyons, 1953). The radiographic appearances of massive fibrosis have been reported by Cavigneaux, Charles, Fuchs, and Tara (1950) in a woman in a rubber works; by Pruvost (1946) in a couturier ; and Even, Sors, and Colbert (1952) in two workers exposed to talc. Alivasatos, Pontikakis, and Terzis (1955) described three cases occurring after only 18 months', two, and three years' exposure respectively in talc factory workers in Greece.

The first example of talcosis in the British literature confirmed by pathological and mineralogical examination was that of McLaughlin and others (1949). This was in a workman in a rubber factory who died of rheumatic heart disease. There were nodular small fibrocellular aggregates throughout the lungs, containing numerous doubly refractile, short needle-shaped fibres, which the authors considered to be an unusual form of talc particle. It has been pointed out by Nagelschmidt (1956) that in fact the needle-shaped particles were those of the normal flat talc plates which were standing on edge in the sections, those lying flat not being visible with a polarizing microscope. This phenomenon was also seen in the case described here. Despite the acicular form of the particles in polarized light, the electron microscope showed the usual plate-like forms of the mineral. There was a negligible amount of free silica and numerous asbestos-like bodies.

The most comparable case in the literature is that of Di Biasi (1951). A man of 54 had been exposed to talc under similar circumstances in casting accumulator plates for 17 years. At the end of this time he became progressively disabled by dyspnoea and died in congestive heart failure. There were small nodules throughout the lungs and masses reaching the size of an orange in the lower parts of the upper lobes and the upper parts of the lower lobes. Histologically the fibrous masses contained large structureless areas in which were large numbers of talc particles. The talc plates were of the average size of $4 \mu$, with some up to 10 and a few to $20 \mu$ in diameter. No free silica was found chemically or by $x$-ray diffraction in these lungs. There was no cavitation. A few "atypical tubercles" are mentioned as being present. Beintker and Meldau (1949) studied material from Di Biasi's case and showed erosion 
of talc particles from the lung compared with those inhaled. This was not seen in the present case.

An unusual syndrome was described in one patient by Jaques and Benirschke (1952). In addition to fibrocellular masses up to $4 \mathrm{~cm}$. diameter in the lungs, there were giant-celled granulomata in the myocardium and in the gastric mucosa. Despite a heavy exposure to talc, finishing eight years before death, hardly any talc was found in the lesions. The authors thought that sarcoidosis could be ruled out. The tuberculin skin test had been negative and no evidence of tuberculosis could be found at necropsy.

Recently Schepers and Durkan (1955) have reported post-mortem studies of the lungs of seven miners and one miller of talc. Only two of these had no concomitant exposure to quartz. Those with massive collagen formation were those with the highest quartz contents in the lungs. They found cellular and stromal necrosis in the masses, which, they suggested, might be due to histoplasmosis, although there was no evidence that this was so. There were numerous fibres $20-50 \mu$ long and many asbestos-like bodies. Schepers suggests that both were derived from tremolite, which was present in large quantities with the talc deposits of that district.

Schepers also published the results of dusting experiments in animals carried out at the Saranac Lake Laboratories. These showed that, on intratracheal insufflation in guinea-pigs, tremolite was actively cytogenic and fibrogenic, especially in long fibre form $(20-50 \mu)$. Pure talc was found to be mainly cytogenic. He suggests that tremolite may be the agent responsible for pneumoconiosis from commercial "talc." However, neither in the case reported here, nor in that of Di Biasi, was any tremolite found, and in both there were relatively few asbestos-like bodies.

An unusual aspect of the case being reported was the development of cavities. Their appearance suggested that they may have formed by confluence of the necrotic areas so prominent in the fibrous masses. The role of tuberculosis cannot be definitely assessed. Acid-fast bacilli were never found during the time the cavities were developing, and there was no evidence of tuberculosis histologically. On the other hand, one of the patient's sons developed tuberculosis, although possibly coincidentally. It is possible that necrosis and subsequent cavitation could be explained on the basis of ischaemia, to which the vascular changes might contribute.

Another feature was the prominence of the foreign body cellular reaction. It is now well known that this may occur in other tissues as a reaction to talc, such giant-celled granuloma having been found in the peritoneal cavity after laparotomy, and in a variety of other situations. Talc has been used to promote pleural adhesions (Bethune, 1935), and a similar histological picture may be found after this procedure (Hinson, 1956). Although macrophage reaction and ill-formed giant cells have been present in most cases of talc pneumoconiosis described, it does not appear to have formed the giant-celled granuloma to the same extent as in this case.

\section{SUMMARY}

A man who had been exposed for 10 years to talc dust developed radiological evidence of pulmonary fibrosis. This later became confluent and cavitation appeared. The degree of disability was negligible in comparison with the state of the lungs. The clinical course and necropsy findings are described.

My thanks are due to Dr. H. V. Morlock, M.C.. for permission to publish the clinical findings and radiographs; to Dr. Kenneth Perry, Dr. K. F. W. Hinson, and Dr. Francis Camps for reading the draft and for their kind advice; to Dr. G. Nagelschmidt for the mineralogy and his great interest; to $\mathrm{Mr}$. R. A. Kimber for the technical work and photography; and to the Ministry of Fuel and Power for permission to publish Figs. 12 and 13.

REFERENCES

Alivisatos, G. P., Pontikakis, A. E., and Terzis, B. (1955). Brit. J. industr. Med., 12, 43.

Beintker, E., and Meldau, R. (1949). Klin. Wschr., 27, 607.

Bethune, N. (1935). J. thorac. Surg., 4, 251.

Caplan, A. (1953). Thorax, 8, 29.

Cavigneaux, A., Charles, A., Fuchs, S., and Tara, S. (1950). Arch. Mal. prof., 11, 34.

Di Biasi, W. (1951). Virchows Arch. path. Anat., 319, 505.

Dreessen, W. C., and Dalla Valle, J. M. (1935). Publ. Hlth Rep. (Wash.), 50, 131

Even, R., Sors, C., and Colbert, J. (1952). Sem. Hôp. Paris, 28, 2936 Hinson, K. F. W. (1956). Personal communication.

Jaques, W. E., and Benirschke, K. (1952). A.M.A. Arch. industr. Hyg., 5,451 .

Lyons, H. A. (1953). Milit. Surg., 113, 393.

McLaughlin, A. I. G., Rogers, E., and Dunham, K. C. (1949) Brit. J. industr. Med., 6, 184.

Mann, B., and Deasy, J. B. (1954). Brit. med. J., 2, 1460.

Merewether, E. R. A. (1934). Ann. Report of the Chief Inspector of Factories for 1933, p. 63. London.

(1935). Ann. Report of the Chief Inspector of Factories for 1934, p. 65.

Millman, N. (1947). Occup. Med., 4, 391.

Millman, N. (1947). Occup. Med., 4, 391 .

Perry, K. M. A. (1947). Thorax, 2, 91.

Porre, F. W., Patton, J. R., and Hobbs, A. A. (1942). Amer. J. Roentgenol., 47, 507.

Pruvost, P. (1946). Bull. Acad. Méd. (Paris), 130, 202.

Reichmann, V. (1944). Arch. Gewerbepath. Gewerbehyg., 12, 317.

Schepers, G. W. H., and Durkan, T. M. (1955). A.M.A. Arch industr. Hlth, 12, 182, 317 .

industr. Hlth, 12, 182, 317. Greenburg, L. (1943). Industr. Bull. (N.Y.), 22, 434 .

Shatalov, N. N. (1954). Gigiena, No. 2, p. 29.

Sorel, R., Lasserre, J., and Salvador, R. (1943). Bull. Soc. méd. Hôp. Paris, 59, 267. 